Institutional logics as a contribution to social ontology

Alistair Mutch, Nottingham Trent University. Alistair.mutch@ntu.ac.uk. https://orcid.org/0000-00028054-6649. 
Abstract

The concept of institutional logics, as developed by Roger Friedland and articulated in the management and organization studies literature, is brought into alignment with Margaret Archer's morphogenetic framework. Drawing on examples from studies of law and organizations, the article argues for the value of conceptualizing society as comprising a set of institutional orders, each operating with a distinctive logic. Logics are made evident in practices and the article argues that those working in the critical realist addition need to pay more attention to taken for granted practices in their analyses.

Key words: institutions; institutional logics; morphogenesis; practices; law; history 
In this article, I suggest that the approach known as 'institutional logics', an important strand of thinking in Management and Organisation Studies (MOS), has the potential to enrich the social ontology deployed by social theorists in the critical realist tradition. I start by outlining the nature of social ontology, with particular emphasis on Margaret Archer's morphogenetic framework. Responding to some critiques of the place of culture within this framework, I suggest that the work of the religious sociologist Roger Friedland, specifically his conceptualization of institutional logics, contains much of value. I outline his conception of such logics being bundles of substance and practices before turning back to critical realism for some supporting resources. I then illustrate the value of logics by considering the case of law as a distinctive logic, drawing on both legal scholarship and some examples from the MOS literature. I then review some potential objections before arguing that an institutional logics approach helps understand sources of social change, directs our attention to the relatively neglected category of practices and suggests intriguing new domains for social investigation.

\section{Social ontology}

For Margaret Archer (2013: 9), social ontology 'effectively defines the constituents of the social world'. For those in the critical realist tradition, the social world is emergent from but not reducible to the actions of human beings. Once emergent, aspects of the social world form the context in which actors are involuntarily placed and which shape, but do not determine, their actions. Much of the attention in this tradition, especially in the work of Archer, has been concerned with elucidating the relation between structure and agency. A concern with social ontology, with the nature of social being, raises concerns about 'categories such as social structure, social institutions, rules, conventions and norms' (Lawson, Latsis and Martins, 2007: 5). One such category is that of the 'institution', as in the following formulation from Archer: 'there is no ready fund of analytical terms for designating the components of the cultural realm corresponding to those which delineate parts 
of the structural domain (roles, organizations, institutions, systems, etc.)' (Archer 1996: 1). There are two important elements of this definition. One is that institutions are distinguished from organizations. Implicit here in the ordering is that institutions stand above organizations and that will be the approach adopted here (as against much of the contemporary work in MOS). Secondly, Archer has institutions as part of the realm of structure rather than culture. In what follows, I am going to challenge that distinction.

However, I am going to follow in the insistence of Archer that any practical social theory has to consider the interaction of structure, culture and agency. It is the case, however, both that Archer's later work is far more concerned with agential reflexivity and that the nature of both structure and culture could stand further explication. I recognise here that Archer's work associated with her Centre for Social Ontology has been concerned with the nature of contemporary society (Archer and Morgan, 2020). Here the focus has been on speculation that contemporary society might be moving into a morphogenic phase, powered by the generative mechanism of cultural and structural variety (Archer, 2013). This article is not concerned with the validity or otherwise of that argument, but rather with considering whether developments with MOS can help us better specify the nexus of culture and structure that shapes the context for social action. Hardy (2019) has argued that culture is underdeveloped in Archer's account. This perhaps seems rather a harsh criticism. There are two observations. One is that it was culture rather than structure that was the starting point for Archer's exploration of morphogenesis, albeit one that was subsequently modified to be consistent with her exploration of the relationship between structure and agency in her most influential book (Archer $1995,1996)$. That she has subsequently gone on to explore the character of agential reflexivity in great detail should not obscure the fact that her conceptual framework has to be treated as an overarching one, where she continues to insist of the necessity to consider structure, agency and culture in any concrete exploration of social reality (as Archer herself points out (Archer, 2019). The second is that it is hardly Archer's fault that others have tended to deploy the more structural emphasis when they come to apply her frameworks. Certainly this appears to be the case in MOS, 
where there are few examples of attempts to develop the notions of culture (for an exception, see Mutch, 2009). Archer's (1996) argument is one that is developed at a very high level of abstraction, based on examples of formal debate, such as the challenges posed by the legacy of Classical Antiquity for Western Christianity explored by Durkheim. Archer's account then produces a series of relationships based on logics of complementarity and contradiction both at the level of the cultural system and the socio-cultural system. This is both richer than Hardy acknowledges but at the same time more challenging. I seek to show that conceptualizing social ontology as a set of inter-related institutional orders, each characterised by blends of material practice and cultural symbols and governed by a distinctive logic enables us to identify more precisely sources of tension that can shape the resources available to and capacities for action of social actors.

\section{Roger Friedland and institutional logics}

Roger Friedland is a sociologist of religion whose impact has been far greater in MOS than in his own discipline area - not that disciplinary boundaries have much relevance to his work. In his home discipline he has worked on the character of religious nationalism, especially in a detailed examination, with Richard Hecht, of the contested nature of Jerusalem as a place of sacred meaning for a number of faiths (Friedland and Hecht, 1996). As his work has progressed, he has examined a wide variety of empirical contexts, ranging from contemporary practices of love to sexuality and architecture (Friedland et al, 2014; Friedland and Zellman, 2006). At the heart of these explorations has been a concern with the passionate and erotic dimensions of belief, always with the notion of institutional logics at the centre.

His first exposition of the notion of institutional logics came with the contribution of an essay, coauthored with Robert Alford, to an edited volume on institutional theory in 1991 (Friedland and Alford, 1991). This extremely influential collection became something of a foundational document in the growth of new institutional theory. Most of the chapters emerged from organizational theory and shared a focus on the problematic of legitimacy but the Friedland and Alford chapter was 
different and distinctive in its concerns. It was concerned to problematise the concept of institutions from, in part, traditions shaped by Marxist historical materialism. However, it rejected crude notions of base and superstructure in which cultural constructions were built on a material base and, in the crudest forms, were simply a mirror of material interests. For Friedland and Alford, in sharp contrast to much of the discussion in MOS (and aligned with the Archerian hierarchy), institutions operated at the societal level. They are few in number and are enduring in character. They give meaning to the practices in which people engage in their social and organizational life. They are combinations of material practices and cultural symbols, giving rise to characteristic logics. These are not formal logics of cause and effect or mutually related propositions. Rather, they are logics in the sense of providing guides to action, of suggesting courses of action that are more powerful for appearing obvious and taken for granted. They condition action rather than determine it. As Archer (1995) points out in her discussion of situational logics, these frame opportunities but do not determine them. Actors are always able to do other but only if they are willing to incur the opportunity costs generated by so doing. Logics are also, on Friedland's account, not seamless and homogenous but contain contradictions that provide cracks which can be exploited to promote change.

Friedland and Alford were anxious to preserve autonomy for their institutional spheres, whilst recognising inter-connections. Each, they argued, had their own distinctive laws of motion. It is also important to remember, in the context of our earlier discussion, that this was a view from outside the world of organizational studies, indeed one in which religion and the lessons derived from its study were of considerable importance. They suggested in this initial essay that "The central institutions of the contemporary capitalist West - capitalist market, bureaucratic state, democracy, nuclear family, and Christian religion - shape individual preferences and organizational interests as well as the repertoire of behaviors by which they may attain them' (Friedland and Alford, 1991: 232). What they did not specify were any criteria by which this list of institutions was constructed, which gave licence for subsequent scholars in MOS to take these ideas and shape them through the prism of existing work on organisations. 
While it is not the main focus of this article, it is worth acknowledging both that Friedland's work has had more impact within the domain of MOS that in his home discipline and that the use of his work has diverged sharply from his approach as it has become more influential within MOS. Adopted initially by Patricia Thornton in her work on academic publishing, a version of institutional logics has become one of the major perspectives in institutionalist work (Thornton, 2004; Thornton, Occasio and Lounsbury, 2012). In reviewing a book-length summation of this version, Friedland noted 'Just for the record, they have done a creative reading of what they call Robert Alford's and my "interinstitutional system" in which I sometimes do not recognize my own understanding of these logics' (Friedland, 2012: 584). In particular, he deplored the absence of the category of 'value', arguing that, for him, 'An institutional value founds the ontology of the central object or state of being, around which normatively enforced practices are organized through constellations of roles and hence constitute the resources through which powers are afforded' (Friedland, 2012: 586). In noting the emphasis that Archer has placed on attachment to values in motivating action and conditioning reflexivity, we leave behind for the present the MOS literature and explore how Friedland has taken his views in a very different direction, one with value at its heart.

In developing his views, again partly in parallel with developments in MOS but without the concerns of MOS as central, Friedland has drawn on two sets of resources. One is a turn to Weber's notion of 'value spheres'. Weber's essay on 'religious rejections of the world and their directions', first published in 1915, took as its starting point Indian religious forms, the most developed form, he argued, of religion rejecting the world (Weber, 1948). In order to do this, he suggested a number of ideal types of 'life orders' against which to contrast the claims of religion. These value spheres consisted of different ways of being in the world and Weber considered them in turn to explore the tensions between them and religion. These spheres of value were: kinship; economic; political; aesthetic; erotic and intellectual. What is important for Friedland is that each has its own laws of motion, something he develops with the second set of resources, Aristotelean essentialism. As Scot Meikle (1985) argues in a trenchant account, essentialism has become a dirty word. Meikle's 
concern was with the Aristotelian influence on the development of Marx's categories, where he argues that Marx's essentialist materialism

means (a) that there are real natures or essences which are not 'reducible' to 'simples', (b) that coming to identify them and know them involves tracking down what is general, universal or essential in the phenomena or 'finite real', and (c) that that has to begin with an investigation of the facts of the finite real itself in order to discover (it cannot be known a priori) what is truly the general within it, so that (d) the finite real, the reality itself, can then finally be comprehended in the light of the general, the universal or the essence, that the empirical investigation turned up (Meikle, 1985:44).

We can see here some illuminating parallels with the critical realist enterprise, not least in Meikle's conclusion 'of the primacy of ontology over epistemology. Our language, and our talk about events, is possible only because the world as it is is a world containing entities that persist through change' (Meikle, 1985: 174). Friedland uses the term 'substance' to describe the essential quality that makes a thing that type of thing and not another. For him, substance is the motivating value of an institutional order, the value for the sake of which action is taken. It is not a material quantity and indeed is likely to recede further from view as it is sought for. It is "immanent in the practices that organize an institutional field, values never exhausted by those practices, practices premised on faith" (Friedland, 2009: 61). From the combination of substance and practices emerges institutional logic, "a bundle of practices organized around a particular substance and its secondary derivatives from which the normativity of those practices is derived" (Friedland, 2009: 61). While derived from his work on religion, Friedland seeks to 'to move from religion as an institution to institution as a "religious" phenomenon' (Friedland 2009: 49). From such a move he concludes that Institutional substances are the sacred core of each field, unobservable, but socially real. They are the god-terms of social life, the limited set of things "for-the-sake-of-which" we live our lives, what Augustine referred to as that thing which is "enjoyed," or loved for its own 
sake, unchangeable, eternal and majestic-the Trinitarian God in his case - as opposed to those changeable and uncertain things which are loved because they enable one to possess other objects, and hence not enjoyed, but used (Friedland, 2018: 1391).

'The worldhood of the world is composed of a configuration of institutional logics' argues Friedland (2018: 1393) but he does not specify what that configuration consists of nor how it might be established. My argument in what follows is that drawing on some of the resources of critical realism we can sketch out some criteria for establishing institutional configurations at a general, abstract level. In so doing, I am not claiming that Friedland is a critical realist, just that many of his formulations are consistent with that tradition. They are useful tools to think with, tools which might in turn cause us to modify our conceptualisation of social ontology.

\section{Persons and institutions}

My staring point here is the work on the nature of the person carried out by both Archer and Christian Smith (2010). Archer places considerable stress on the distinction between a sense of self and concepts of the self. In her discussion of ontogeny the human infant experiences the external world, both persons and objects, through touch, triggering the sense of me/not me (Archer, 2000). This realisation of an embodied existence independent of others gives rise, argues, Archer to a sense of self. This sense of self is prior to a concept of self. Such a formulation is consistent with the arguments of the neurophysiologist Antonio Damasio (2000). He argues that the constant, nonconscious monitoring of body states gives rise to what he terms a 'proto-self'. Consciousness arises when this monitoring encounters objects that prompt feelings, feelings that form the sense of self. In turn, this core consciousness is the basis for the extended consciousness that underpins the autobiographical sense of self. 'Autobiographical memory,' he suggests, 'develops and matures under the looming shadow of an inherited biology. However, unlike the core self, much will occur in the development and maturation of autobiographical memory that is not just dependent on, but is even regulated by, the environment' (Damasio, 2000: 229). Building on such foundations, concepts 
of self, which can vary in time and space, are developed and shared through language. Such language is learned in social environments over extended periods of time. However, the sense of self that endures means that for critical realists persons are subjects, not the decentered objects of discourse that are proposed by the anti-humanist philosophies of continental Europe. As Smith puts it,

By person I mean a conscious, reflexive, embodied, self-transcending center of subjective experience, durable identity, moral commitment, and social communication who-as the efficient cause of his or her own responsible actions and interactions-exercises complex capacities for agency and intersubjectivity in order to develop and sustain his or her own incommunicable self in loving relationships with other personal selves and with the nonpersonal world (Smith, 2010: 61).

The capacities that such synchronous emergence supplies are the building blocks of personhood but do not themselves constitute that personhood. They include, besides consciousness, the capacity for memory and language, on which other capacities, such as those of imagination and abstract conceptualisation are built. (Smith (2010) has an extensive list of these capacities). Some of those capacities are shared with other animals, but it is the distinctive combination of these that makes for emergent personhood. The capacity for both imagination and abstraction gives rise to the search for meaning and the importance of belief. Belief is often associated with the key institution of religion, but it is, argues the theologian Graham Ward (2014), primordial, based on our embodied engagement with each other and the world. Drawing on both neuroscience and literature, he argues that belief is anterior to knowledge and, indeed, to faith. Although the work of a theologian, this is not a theological argument. Rather an inbuilt orientation to believe provides the capacity for religious faith, but also for other forms of belief. Such capacity belief then maps on to the creation of social structures, such as institutions. 
For Marx, argues Meikle (1985: 58), humans are 'a natural kind; a species of the mammalian order, whose essence is differentiated from others of that and other orders by the essential properties of being conscious and social.' This impels them to satisfy their being through collective arrangements. For Smith, social structure emerges from the gap between human wants, desires and needs and the finite capacities that individuals possess. As he argues

Humans are profoundly finite creatures, in both body and mind. The tensions arising between human capacities and human limits - between the vastly capable and severely finite in human life-give rise through emergence to creative patterns of lived practice that often solidify into what we call social structures. Social structures are not agreed upon contracts made by autonomous exchange partners, nor are they illusions of facticity appearing falsely to socially constructed and constructing actors as more real than they are. Social structures are real entities with causal powers generated through emergence from the tension created between human capacities and limits as given by the nature of the real world (Smith, 2010: 18).

It is Friedland's argument that, once emergent, such social structures become motivated by passionate attachment to the values that are immanent in characteristic and distinctive practices. On the basis of these arguments I have suggested that institutions emerge from the embodied relationships that humans have with each other and with the natural world (Mutch, 2018, 2019). I use history to suggest that at a level of generality some configuration of such institutions characterizes human societies, even though what such configurations are and the relationships between their constituent parts varies in concrete conjunctions of time and space, as explored in more detail below. In his analysis of the nature of professional work, Friedson examines its intersection with what he terms the 'core disciplines' of social life. He sees these as 'bodies of knowledge and skill which address perennial problems that are of great importance to most of humanity' (Friedson, 2001: 161). '[M]edicine, law, and religion exemplify such disciplines,' he argues, 
'dealing as they do with relief from pain, illness, and disability..., the just resolution of disputes and maintenance of social order, and a comforting relationship to the perennial misfortunes of life and the inevitable prospect of death' (Friedson, 2001: 161). They are characterized by attachment to what he terms 'transcendent values', in this case 'Health, Justice, and Salvation' (Friedson, 2001: 161). He goes on to examine other transcendent values such as 'Beauty, Truth, or Knowledge' (Friedson, 2001: 167). History is a way of tracing the existence and evolution of these responses to 'perennial' aspects of the human condition. We can group them into three categories. There are those institutions which arise from the struggle for embodied existence in the natural world, leading to solutions for reproduction, material existence and physical well-being: family, economy and medicine. There are institutions arising from a desire to make sense of that embodied existence: religion, play and knowledge. Finally, human existence is a profoundly social one, albeit emergent from individual engagement with the natural world, and mechanisms have evolved for dealing with social interactions: dispute resolution by physical force, by regulation, or by debate: the military, the law and politics. Each institution possesses a distinctive logic, one which specifies roles and practices characteristic of that logic and given meaning by it.

\section{Institutional logics illustrated: the law}

While each of the suggested logics bears further discussion, I use the law as an illustration, in part because there are some interesting and relevant discussions deriving from the MOS literature. Here, as in other domains, there has been the tendency to view the law as a pale reflection of other domains, an epiphenomenon of political or economic action rather than as an institution possessing laws of motion that are distinctive to the realisation of its virtual substance, in this case justice. Such views correspond to what has been termed the 'law and society' approach, in which law is seen simply as the codification of the results of disputes happening elsewhere. By contrast, work in legal anthropology and comparative law has drawn attention to the notion of 'law for itself', the idea that there are distinctive roles and practices associated with the law that have emerged from its 
development and which condition the degree to which it aligns with social, economic or political imperatives.

Using the 'law for itself' approach in the context of failed attempts to grow the mortgage market in Hungary, Léna Pellandini-Simányi and Zsuzsanna Vargha (2019) draw attention to the way in which the intentions of legislators and economic actors were initially frustrated by legal technicians. While those desiring to grow the market for mortgages saw this as simply bureaucratic obstructionism, investigation of those legal technicians indicated that

When talking about guaranteeing the safety of the bond and the imperative of complying with EU regulation and Hungarian law, bureaucrats are not talking about abstract regulatory styles or traditions. They talk about the concrete 'plumbing' problem of connecting one piece of legislation to the rest that is already in place or will be in place. For these technicians, the legal system was not a pliable tool of political-economic projects. They experienced little personal agency. Rather, they saw themselves as conveying the demands of this interconnected web of laws. Rule-following was less a personal attribute of Ministry employees than an imperative to safeguard legal consistency (Pellandini-Simányi and Vargha, 2019: 9).

What had to happen to make legislation effective in a subsequent round was to pay more attention to the intricacies of the law as a logic in its own right, one with distinctive practices and roles. In this, the authors echo the much earlier point made by the British Marxist historian E. P. Thompson in his analysis of the 'Black Acts' of eighteenth-century England (laws designed to preserve the game rights of an aristocratic elite). The frustration of the intentions of the lawmakers drew attention to the role of juries as part of common law systems. Actors 'will, on occasion,' argued Thompson, 'act not according to their own interests but according to the expectations and values attached to a certain role. The role of juror carried (and still carries) such an inheritance of expectations' (Thompson, 1977: 189). As Thompson argued, in a point that was controversial amongst many Marxists, 
The law may also be seen as ideology, or as particular rules and sanctions which stand in a definite and active relationship (often a field of conflict) to social norms; and, finally, it may be seen simply in terms of its own logic, rules and procedures - that is, simply as law. And it is not possible to conceive of any complex society without law (Thompson, 1977: 260).

That law generates distinctive practices that require attention is also illustrated by another article in the MOS literature. In a careful examination of evolving legal practices in Anglo-German law firms, Smets, Morris and Greenwood (2012) draw attention to differences in the drawing up of contracts. Contracts drawn up by German lawyers were sparse in form, resting on the specification of standard terms in legal codes. By contrast, English lawyers produced dense contracts with many clauses. Thanks to their socialization, German lawyers saw their duty as primarily to the upholding of the status of law as a series of codes.

It is in anticipation of court verdicts that they identify statutes that apply to a specific case and ensure contracts align with them. Hence, when confronting legal problems, German lawyers are predisposed to forensic analysis, examining whether, not how, a desired outcome can be achieved under the constraints of law. They draft slim documents with implicit recourse to codified statutes and only selectively signpost agreed deviations from nonmandatory norms (Smets, Morris and Greenwood, 2012: 885).

By contrast, English lawyers, trained in a common law system that privileges case law, saw their primary duty as being to their clients and so, conclude Smets et al (2012: 886), 'Their approach to legal problems is highly pragmatic and, in their drafting, they produce comprehensive documents that can easily reach several hundred pages for a single transaction, spelling out every clause and remedy.' For such lawyers, the attitude of their German counterparts prompted a reaction similar to that of the politicians and business leaders faced by Hungarian legal technicians. As English partner cited by Smets et al complained '[They] are not prepared to think beyond what they know or think beyond what they have seen in the books. Whereas a British lawyer has been taught to think beyond 
just the law and how you can ... structure around issues rather than just saying "can't be done"' (Smets, Morris and Greenwood, 2012: 886). What these conflicts initially led to was mutual incomprehension, but emergent from this over time were hybrid practices of contract formulation that sought to blend the two versions of legal logic. There are two implications of this example for our discussion. One is that it confirms the creation of roles and the conditioning of action by distinctive logics. The second is that there is no pure form of the institutional logic of law. Rather, there can be contrasting practices that emerge from different historical trajectories.

The contrast here is between the common law systems associated with Anglo-American legal practice and the civil law traditions of continental Europe (Vranken, 2015). The contrast is rendered less sharp by the increasing creation of laws by legislation but comparative legal investigations indicate that while this might lead to a commonality of content, procedures remain distinct and important. How law is carried out is therefore often more important than what law formally is. The distinction is often characterised as one between an adversarial approach in the common law versus an inquisitorial one in civil law traditions. In the former, arguments are played out between the legal representatives of the contending parties, with judges acting as impartial mediators upholding the 'rules of the game'. By contrast, in an inquisitorial system judges are an activist part of the search for the facts of the matter, especially in criminal proceedings.

These differences give rise to significantly different practices. Thus, Bernhard Grossfeld contrasts the style of judgments in the contending systems.

In England, the higher courts traditionally give their opinions orally in a highly personal way. Even today, opinions in the House of Lords are called 'speeches'. In France, judges produce short and abstract written versions, 'more geometrico'. In Germany, they elaborate long written 'dissertations' in the particular grammatical style of the Latin-language tradition and, thus, quite often in bad German (Grossfeld, 2013: 160). 
The focus on orality in the common law tradition is matched by the sense of drama in the courtroom. As the English lawyer Jeremy Lever (1999: 299) observed, in the common law tradition 'the judge or judges come in, the house lights are dimmed, the curtain goes up and the audience settles down to watch the play, though it may react from time to time to ensure that the rules governing the drama are observed and to clarify aspects of the action.' By contrast, in civil law traditions the court hearing is just one part of an overall process of discovery. 'On the Continent,' notes Grossfeld, 'we see a continuing exchange of written texts, punctuated whenever necessary by proof-taking hearings, but with no dramatic climax' (Grossfeld, 2013: 176). Different legal systems, thus, generate distinctive practices and it is in those practices that the substance of the logic at the heart of each is manifested. We have to look beyond formal content, that is, in each of our logics to observe the mechanisms at work.

The focus on the procedural logic of taken for granted practices also can indicate assumptions that run across logics in an inter-institutional configuration. For example, it is possible to detect an emphasis on codification in French approaches that mirrors the emphasis on system and codes in civil law practices. For example, an investigation of the formation of the Paris Opera in seventeenth century France by Victoria Johnson finds that royal academies, 'an organizational form sponsored by the king and traditionally devoted to private discussion among academy members', were seen as the to-hand template for the organization of the Paris Opera (Johnson, 2007: 104). In turn, those academies promoted a logic of centralized political control, in which the 'main goal was codification of guidelines for production in an academy's given area of cultural or scientific specialization' (Johnson, 2007: 108). A focus on codification and systematisation, what Bourdieu and Passeron (1977: 148) describe as 'the typically French religion of classification', thus seems to be an enduring organising principle that binds together the institutional orders that characterise French society. 


\section{History and logics}

One could, of course, carry out a similar discussion for each of the institutions suggested above. However, there is enough in the discussion of the law to illustrate some of the key dimensions that an institutional logics perspective draws our attention to. It suggests that there are distinctive practices and roles within each logic that are proper to that logic and are engaged in, often unconsciously, for the sake of a substantive value which animates action, even if it can never be reached. Before considering how such a perspective aligns with Archer's formulations, it is worth noting a number of further implications that flow from an institutional logics perspective. In drawing out such implications it important to notice the centrality of temporality. A historical approach is central to identifying both the emergence of logics and their particular configuration at specific conjunctures of time and space.

It was Weber who noted

The priesthood, as the only agents capable of conserving tradition, took over the training of youth in the law and often in purely administrative technologies, and, above all, in writing and calculus. The more religion became book-religion and doctrine, the more literary it became and the more efficacious it was in provoking rational lay-thinking, freed of priestly control (Weber, 1948: 351).

From this emerged the universities, firstly as specialist centres of theological training and then as broader centres. Over time there emerged, as Archer explores, a set of distinctive practices that coalesce around education, driven by adherence to ideals such as curiosity and a search for the truth that, while contested, amount to a distinctive logic.

The work Weber is often most closely with is his much-debated and still contested 'Protestant Ethic' thesis. What this reminds us is that in Western Christianity there were many centuries when, in broad terms, the institutional logic was consistent with an undifferentiated institution, in which the Catholic church provided both the authorized belief system and the approved practices, as well as 
the only legitimate organizational form. However, the Reformation saw the emergence of competing formulations in all these dimensions (MacCulloch, 2004). At least three major competing formations, each with their own formal statements of belief, their own distinctive practices and their own organizational form, came into existence: the Lutheranism that characterised much of Germany and northern Europe; the Calvinism of the Netherlands and Scotland; and the Episcopalianism of England. From this time, any consideration of 'religion' as an institution within Christianity has to consider the particular form that is under consideration.

This specific form then comes into relationship with the other institutions that constitute society. In some cases this forms a complementary relationship. In Scotland, for example, one can trace a mutually supportive relationship between religion, law and education (Mutch, 2015). Scots law drew heavily on a Roman law tradition, in which there was, by European standards, an early attempt to codify legal rules and promulgate these in written form. This in turn rested on widespread literacy in an educational system which featured the same focus on starting from first principles that characterised both the law and the particular religious form of the Church of Scotland. In turn, that church both monitored and encouraged the growth of a basic education system and a higher education system. This distinctive complex of institutional forms can be seen in sharper focus when contrasted with the position in England, where a common law tradition and a state church featuring both a nominal hierarchy and a strong element of devolved authority fostered the enduring influence of custom and tradition. This was reinforced by an ad hoc and fragmented educational system, whose pinnacles in the form of the universities of Oxford and Cambridge remained profoundly shaped by and limited to particular religious traditions. In concrete analysis, that is, we have to move from highly abstract concepts, deliberately drawn at a sufficiently general level to permit comparative analysis to historically grounded investigations that use logics as an analytical device while paying full attention to the accidents of history. As Archer argues in putting the case for 'analytical narratives of emergence' 
analytical narratives of emergence can never ever be grand precisely because the imperative to narrate derives from recognizing the intervention of contingency and the need to examine its effects on the exercise or suspension of the generative powers in question since outcomes will vary accordingly but unpredictably. On the other hand, analytical narratives are obviously distinct from any version of historical narration tout court, for although social realists in general have no difficulty in accepting the strong likelihood of uniqueness at the level of events, the endorsement of real but unobservable generative mechanisms directs analysis towards the interplay between the real, the actual and the empirical to explain precise outcomes (Archer, 1995: 343).

In providing such accounts, it is here suggested that the institutional logics perspective provides valuable conceptual resources. In the next section, I consider how the approach I have been discussing aligns with Archer's conceptualisation of social ontology as the relationship between structure, culture and agency.

\section{Morphogenesis, logic and social ontology.}

While, as we have seen, Archer sees institutions as a central part of social ontology, she is sceptical of the possibility of defining what 'core' institutions might be (Archer, 1995: 218). That might seem to immediately dismiss the argument presented here. However, it seems important to have some sense of what institutions might be. In addition, the candidates presented here are outlined at a high level of abstraction. The suggestion is not that they will all be present in any concrete conjuncture, but that the specification of them consisting of substance and practices provides criteria for identifying their specific existence and configuration. History is important here in two ways. One is that it provides us with resources for assessing what the perennial problems of society might be and how they are solved. Secondly, the analytical tool of institutional logics has to be applied in concrete historical instances, where the balance of importance and relations of contradiction or complementary may vary. Of course, the candidate institutions I propose above are open to debate 
but my argument is that the institutional logics perspective provides a valuable resource and one broadly consistent with critical realist approaches.

The approach is also one which chimes with the emphasis on logic in Archer's work. Again, there are two dimensions here. In her work on culture she is anxious to deploy the tools of formal logic to explore how ideas stand in relation to each other. Using such tools can indicate the degree to which ideas have logical entailments, entailments which might not to be apparent to those who seek to mobilize them. This is where the second sense of logics comes in. The items in the cultural system at any point in time form a situational logic which has consequences for those who seek to deploy ideas. They may seize on a specific idea without realising the relations it has with other items in the cultural system. Having made the relationship visible to others, they are then required to either suppress inconvenient elements or to seek to effect repairs at the level of ideas. This idea of situational logics can then be extended to the combination of structural and cultural elements as, for example, in the case of the caste system in India that Archer cites (1995: 221) as a (rare) example of the tight integration of both which in turn promotes social stability over an extended period. However, situational logics can be resisted, if actors are willing to pay the opportunity costs of 'going against the grain'. Hence Archer's interest in way some actors resist the siren call of existing logics and so her exploration of reflexivity.

What an institutional logics approach does is to suggest the ways in which logics are manifest in practices, practices which are often taken-for-granted but which have logical entailments for the nature of the positions available to actors. It is often such practices that travel from one distinctive form of logic to others and in so doing can prompt change. Here, then, is a response to Hardy's critique. If we see society as consisting of a set of interrelated institutions, each powered by a distinctive logic animated by attachment to a substance which can never be reached but which is real and immanent in its distinctive practices, then we have a tool to examine the tensions between different logics. Sometimes these may be complementary and mutually reinforcing, as in the 
emphasis on system and codification in aspects of French society, but more often they can be in contradiction, so supplying both opportunities and resources for social change. However, against this, it is possible to argue that many practices gain their strength from their 'obvious' nature. This then shapes and conditions agential reflexivity in such a way that opportunities for alternatives are simply not evident.

\section{Conclusion}

However thought provoking and useful the institutional logics perspective is in thinking about the character of society, it is not claimed that it provides an exclusive key for social analysis. Rather it has to be combined with other well-established categories of analysis at the disposal of the social theorist, especially the categories of class, gender and ethnicity. In the law, for example, it is clear that the distinctive roles given by the logic, such as the position of judge, have historically been elite positions, in which attachment to legal logic is transversely conditioned by socialisation processes common to elites occupying similar positions in other institutional orders (Zald and Lounsbury, 2010). However, one notes here the qualifier to this provided by other roles, such as that of the juror examined by Thompson. Here elite command of senior positions in the name of a substance like 'justice' is held to account by others who may have a purer conception of what such a value means. Likewise, such elite positions have often been profoundly gendered. One can note, for example, a symbiotic relationship between a belief in a patriarchal male god figure in major monotheisms and male control in family households. However, over time such relationships can be weakened through socio-cultural action. In some denominations in Western Christianity, for example, where female believers have often been in the majority but have been denied access to positions of authority, there are now both female religious and lay in positions previously reserved for men. It is necessary, therefore, to consider the interaction between logics and these other categories of social analysis, interactions which are likely to vary in specific historical conjunctures. 
While there is therefore more work to be done to elaborate these relationships, the logics approach is valuable for those working in the critical realist tradition of social theory in two primary aspects. One is that it draws to our attention to the importance of practices. This is practices, such as routines or rituals, as nouns rather than verbs. That is, while there has been emphasis on practice as the working out of theoretical propositions, a focus on practices turns our attention to the importance of mundane and taken-for-granted practices. This is an important counterbalance to what can often be an emphasis on formal bodies of propositions. In his historical analysis of contrasting working practices in the English and German woollen mills of the nineteenth century, Richard Biernacki points out that theories arise from practices. 'The definition of labor as a commodity,' he argues, 'was recreated day in, day out by a cluster of micro-procedures that did not require the producers to lend their attention to the meaning of labor in order to preserve its shape. The concept was received through experience rather than instruction; it was lived before it was turned to account' (Biernacki, 1995: 434). Practices are therefore not just technical functions, but also cultural signifiers. They cannot be simply 'read off' intellectual discourse. As he puts it '[a]dherence to an ideal did not descend downward from contemplative knowledge of the general but percolated upward from practical knowledge of the concrete' (Biernacki, 1995: 203).

The second aspect is that the formulation of institutional logics presented here, as a response to the gap between human wants, needs and desires and their limited capacities to achieve them, turns our attention to relatively unexplored but nevertheless important aspects of human existence. While Biernacki's account sees culture as a response to economic conditions, here the focus is much broader and emphasises the human capacity and need for meaning making. Hence the perhaps rather unexpected notion of play as a crucial part of social ontology. The Dutch historian Johan Huizinga argued play is 'an absolutely primary category of life, familiar to everybody at a glance right down to the animal level'. Again, there is much more that could be said about each of the candidate institutions presented here, but they provide a way of differentiating what Hardy (2019) sees as a 'fragmented monolith'. Ideas taken from MOS, specifically the work of Roger Friedland, thus offer an 
answer to concerns about the status of culture in Archer's morphogenetic approach. Conceiving of society as a set of interrelated institutions, each combining material practices and cultural symbols is one way of addressing such concerns.

References

Archer, M. (1983) “Process Without System”, Archives Europeenes de Sociologie, 24(4), pp. 196-221.

Archer, M. (1995) Realist Social Theory: The Morphogenetic Approach, Cambridge: Cambridge University Press.

Archer, M. (1996) Culture and Agency: The Place of Culture in Social Theory, Cambridge: Cambridge University Press.

Archer, M. (2000) Being Human: The Problem of Agency, Cambridge: Cambridge University Press.

Archer, M. (2012) The Reflexive Imperative in Late Modernity, Cambridge: Cambridge University Press.

Archer, M. (2013) Social Morphogenesis, Dordrecht: Springer.

Archer, M. (2019) "A reply to Nick Hardy”, Journal of Critical Realism, 18(5), 535-544.

Archer, M. and Morgan, J. (2020) “Contributions to Realist Social Theory: An Interview with Margaret S. Archer", Journal of Critical Realism, 19(2), 179-200.

Biernacki, R. (1995) The Fabrication of Labor: Germany and Britain, 1640-1914, Berkeley, CA: University of California Press.

Bourdieu, P. and Passeron, J. (1977) Reproduction in Education, Society and Culture, London: Sage.

Damasio, A. (2000) The Feeling of What Happens: Body, Emotion and the Making of Consciousness, London: Vintage. 
Friedland, R. and Alford, R. (1991) "Bringing Society Back In: Symbols, Practices, and Institutional Contradictions", in W. Powell and P. DiMaggio (eds) The New Institutionalism in Organizational Analysis, Chicago: University of Chicago Press, 232-266.

Friedland, R. and Hecht, R. (1996) To Rule Jerusalem, Cambridge: Cambridge University Press.

Friedland, R. and Zellman, H. (2006) The Fellowship : the Untold Story of Frank Lloyd Wright \& the Taliesin Fellowship, New York: Harper.

Friedland, R. (2009) “Institution, Practice and Ontology: Towards A Religious Sociology", Research in the Sociology of Organizations, 27, 45-83.

Friedland, R. (2012) “Book review: Patricia H. Thornton, William Ocasio and Michael Lounsbury 2012 The Institutional Logics Perspective: A New approach to Culture, Structure, and Process", M@n@gement, 15(5),582-595.

Friedland, R. Mohr, J., Roose, H and Gardinali, P. (2014) “The Institutional Logics of Love: Measuring Intimate Life", Theory and Society, 43, 333-370.

Friedland, R. (2018) “What Good Is Practice?: Ontologies, Teleologies and the Problem of Institution", M@n@gement, 21(4),1357-1404.

Friedson, E. (2001) Professionalism: The Third Logic, Cambridge: Polity.

Gerth, H. and Mills, C. (1948) From Max Weber: Essays in Sociology, London: Routledge \& Kegan Paul.

Grossfeld, B. (2013) “Comparatists and languages", in P. Legrand and R. Munday (eds.) Comparative Legal Studies: Traditions and Transitions, Cambridge: Cambridge University Press.

Hardy, N. (2019) “Integrating Archer and Foucault”, Journal of Critical Realism, 18(1), 1-17.

Huizinga, J. (1949) Homo Ludens: A Study of the Play-Element in Culture, London: Routledge \& Kegan Paul. 
Johnson, V. (2007) "What is Organizational Imprinting? Cultural Entrepreneurship in the Founding of the Paris Opera", American Journal of Sociology, 113, 97-127.

Lawson, C. Latsis, J. and Martins, N. (2007) Contributions to Social Ontology, London: Routledge.

Lever, J. (1999) "Why Procedure is More Important than Substantive Law", International and Comparattive Law Quarterly, 48, 285-301.

MacCulloch, D. (2004) Reformation: Europe's House Divided 1490-1700, London: Penguin.

Meikle, S. (1985) Essentialism in the Thought of Karl Marx, London: Duckworth.

Mutch, A. (2009) "Dominant Logic, Culture and Ideology", Research in the Sociology of Organizations, 27, 145-170.

Mutch, A. (2015) Religion and National Identity: Governing Scottish Presbyterianism in the Eighteenth Century, Edinburgh: Edinburgh University Press.

Mutch, A. (2018) "Practice, Substance and History: Reframing Institutional Logics", Academy of Management Review, 43(2), 242-258.

Mutch, A. (2019) Reframing Institutional Logics: History, Substance and Practices, London: Routledge.

Pellandini-Simányi, L. and Vargha, Z., (2019) “Legal Infrastructures: How Laws Matter in the Organization of New Markets", Organization Studies, in press.

Smets, M., Morris, T. and Greenwood, R. (2012) “From Practice to Field: A Multilevel Model of Practice-Driven Institutional Change", Academy of Management Journal, 55(4), 877-904.

Smith, C. (2010) What Is a Person? : Rethinking Humanity, Social Life, and the Moral Good from the Person Up, Chicago, IL: University of Chicago Press. 
Thornton, P. (2004) Markets From Culture: Institutional Logics and Organizational Decisions in Higher Education Publishing, Stanford: Stanford University Press.

Thornton, P., Occasio, W. and Lounsbury, M (2012) The Institutional Logics Perspective: A New Approach to Culture, Structure, and Process, Oxford: Oxford University Press.

Vranken, M. (2015) Western Legal Traditions: A Comparison of Civil Law \& Common Law, Sydney: The Federation Press.

Ward, G. (2014) Unbelievable: Why We Believe and Why We Don't, London: I. B. Tauris.

Weber, M. (1948) "Religious Rejections of the World and Their Directions", in H. Gerth and C. Wright Mills (eds), From Max Weber, London: Routledge \& Kegan Paul, 323-359.

Zald, M. and Lounsbury, M. (2010) “The Wizards of Oz: Towards an Institutional Approach to Elites, Expertise and Command Posts", Organization Studies, 31(7), 963-996. 